\title{
Roald Amundsen's contributions to our knowledge of the magnetic fields of the Earth and the Sun
}

\author{
A. Egeland ${ }^{1}$ and C. S. Deehr ${ }^{2}$ \\ ${ }^{1}$ Department of Physics, University of Oslo, P.O. Box 1048, Blindern, 0316 Oslo, Norway \\ ${ }^{2}$ The Geophysical Institute, University of Alaska Fairbanks, 903 Koyukuk Ave., Fairbanks, Alaska 99775, USA
}

Received: 29 August 2011 - Revised: 31 October 2011 - Accepted: 8 November 2011 - Published: 10 December 2011

\begin{abstract}
Roald Amundsen (1872-1928) was known as one of the premier polar explorers in the golden age of polar exploration. His accomplishments clearly document that he has contributed to knowledge in fields as diverse as ethnography, meteorology and geophysics. In this paper we will concentrate on his studies of the Earth's magnetic field. With his unique observations at the polar station Gjøahavn (geographic coordinates $68^{\circ} 37^{\prime} 10^{\prime \prime} \mathrm{N} ; 95^{\circ} 53^{\prime} 25^{\prime \prime} \mathrm{W}$ ), Amundsen was first to demonstrate, without doubt, that the north magnetic dippole does not have a permanent location, but steadily moves its position in a regular manner. In addition, his carefully calibrated measurements at high latitudes were the first and only observations of the Earth's magnetic field in the polar regions for decades until modern polar observatories were established. After a short review of earlier measurements of the geomagnetic field, we tabulate the facts regarding his measurements at the observatories and the eight field stations associated with the Gjøa expedition. The quality of his magnetic observations may be seen to be equal to that of the late 20th century observations by subjecting them to analytical techniques showing the newly discovered relationship between the diurnal variation of high latitude magnetic observations and the direction of the horizontal component of the interplanetary magnetic field (IMF $\boldsymbol{B}_{y}$ ). Indeed, the observations at Gjøahavn offer a glimpse of the character of the solar wind $50 \mathrm{yr}$ before it was known to exist. Our motivation for this paper is to illuminate the contributions of Amundsen as a scientist and to celebrate his attainment of the South Pole as an explorer $100 \mathrm{yr}$ ago.
\end{abstract}

\section{A brief biography}

Roald Egelbregt Gravning Amundsen was born near Oslo, on 16 July 1872 and he disappeared on 18 June 1928 while on an airborne rescue mission somewhere in the Norwegian Sea. As the fourth son in a maritime family, his mother was anxious for him to become a physician. He studied along this line until the age of 21 , when his mother died, and he ran to his life's dream of polar exploration. To this end, he became perhaps the pre-eminent polar explorer, having sailed, flown, or skied to the north and south geographic poles, the north magnetic dip pole, and through the northwest and northeast passages.

After receiving his Captain's papers, Amundsen set his sights on the Northwest Passage with the idea that exploration was a scientific enterprise. It is clear from the contemporary and later analysis and publication of the scientific

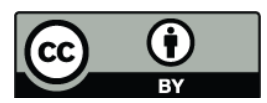

Correspondence to: A. Egeland

(alv.egeland@fys.uio.no) results that Amundsen contributed significantly to the emergence of Norway as a dominant nation in polar meteorology, geophysics, cosmic physics and even ethnography. His entrepreneurial style of exploration extended to his scientific efforts as well. Here we will concentrate on his contributions to the study of geomagnetism, mainly during the 1903-1906 expedition through the Northwest Passage (see e.g. Huntford, 1987).

Amundsen was fascinated by the invisible magnetic field, and learned early on that a compass was important for orientation and navigation, particularly out at sea. During the Belgica expedition, 1897-1999, on which he sailed as first mate, he followed with interest the magnetic observations that were carried out. In his diary on Monday 15 August 1898, he wrote that he and two other crew members were planning to locate the magnetic pole in Antarctica (Kløver, 2009). Unfortunately, that trip was not carried out.

Amundsen started preparation for the Northwest Passage expedition by proposing to locate the north magnetic dip pole (NMDP) (Fig. 1). His background knowledge in geomagnetism was limited. Shortly after he was back from the 


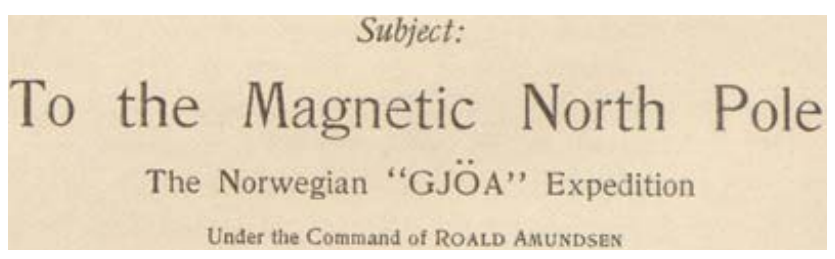

Figure 1. Amundsen's Gjøa expedition received much attention in the international media (from The Los Angeles Times, 1906).

Belgica expedition, he started a more serious education in geomagnetism, both theoretical and observational, before he bought the Gjøa vessel, in 1901. The first scientist to whom Amundsen mentioned his plan to locate the NMDP was the Deputy-Director of the Norwegian Meteorological Institute in Oslo, Dr. Axel S. Steen, who at once became interested (Steen et al., 1933).

Armed with an introduction from Dr. Nansen, he soon made his way to the Director of Deutsche Seewarte near Hamburg, where his goal of geomagnetic studies and locating the NMDP was met with enthusiastic support by Director Georg von Neumayer. Amundsen, together with the Gjøa crew member Gustaf Wiik, spent several months in 1902 and 1903 at the Deutsche Seewarte Institute and at the Magnetic Observatory in Potsdam, near Berlin. Professor Georg von Neumayer and Professor Adolf Schmidt helped considerably both in planning the magnetic observations and ordering the best instruments (cf. Schröder et al., 2010). However, Dr. Steen was his main scientific guide. Mr. Wiik (18871906) was an unusually dedicated worker, the fact of which is clearly demonstrated by inspection of all the magnetic recordings from the expedition. Extreme temperatures and stormy weather never stopped him from his daily routine of the magnetic observations. The goals of the Gjøa expedition was the subject of news reports in many national and international newspapers as the headline from the Los Angeles Times in Fig. 1 illustrates.

\section{Geomagnetism - a brief introduction}

Magnetic fields are a fascinating subject, and the most mysterious of the force fields we experience every day. Only by long-term measurements of the Earth's magnetic field at many observatories can we acquire knowledge about the internal field characteristics. In addition, the changes in the field intensity and direction at individual stations reveals facts about the electric currents in the upper atmosphere, the local geology and the solar activity responsible for the external field variations at that station. These parameters are introduced to models of the internal (geomagnetic) field that are calculated to provide geomagnetic latitude and longitude coordinates for the Earth. Thus, the model geomagnetic field at any point on Earth (including the pole) will not actually correspond to observations of the field at that point, but it will place the station in the context of the total internal geomagnetic field.

The earliest recorded evidence of measurement of the Earth's magnetic field is connected with the direction-finding capability of the compass, and that is dated to the eleventh century in Chinese history (cf. The Encyclopaedist ShonKau, AD 1030-1093), while other sources claim that Chinese had knowledge of the compass two thousand years before Christ. In European literature, the earliest mention of the compass and its application to navigation appeared in two works by Alexander Neekan, a monk at St. Albans (AD 1157-1217). It is mentioned that the "mariners used that means to find their course when the sky was cloudy". The directive properties of the magnets are a reliable direction finder in dark and cloudy weather. Therefore, the geomagnetic field has been linked to navigation for years. Petrus Peregrinus, a French engineer, described the first real experiments in Europe with lodestones in 1269 (Brown, 1949). By the fourteenth century, many sailing ships carried compasses. That the direction to magnetic north, relative to geographic north, differs over most of the globe had also been known for a long time. The difference is called magnetic declination. A more detailed history can be found in the paper: Follow the needle: seeking the magnetic poles, by Good (1991; see also Silverman and Smith, 1994). Chapter XXVI in Chapman and Bartels (1940) monumental work on geomagnetism includes an early history of geomagnetism.

More than $400 \mathrm{yr}$ ago, it was demonstrated that the Earth itself is a giant magnet (Gilbert, 1600, 1958). The Earth's magnetic field is also called the geomagnetic field. To the first approximation the geomagnetic field has a dipole form, with a north and a south pole located near, but not aligned with the south and the north geographic poles, respectively (see Fig. 2). Due to the strong dipolar character, the shielding effect against charged cosmic and solar wind particles is weakest in the polar regions because of the open field lines. There are variations in the main field, resulting in movements of the poles, polar reversals, and changes in the strength of the field. These usually occur over periods of time longer than a year, and are called secular variations. At any single location on Earth, variations in observations of the main field occur on shorter time scales and are due to local ionospheric currents, the local geology and solar activity.

\section{Locating the north magnetic dip pole (NMDP) before 1900}

Before 1900, changes in the position of the north magnetic pole were thought to be important for new sailing routes, particularly from Europe to Asia. Therefore, its location had raised public interest because many people thought (and still do) that compasses point to the pole, despite evidence that the needle is responding only to the local magnetic field. Models of the geomagnetic field differ in detail from the 

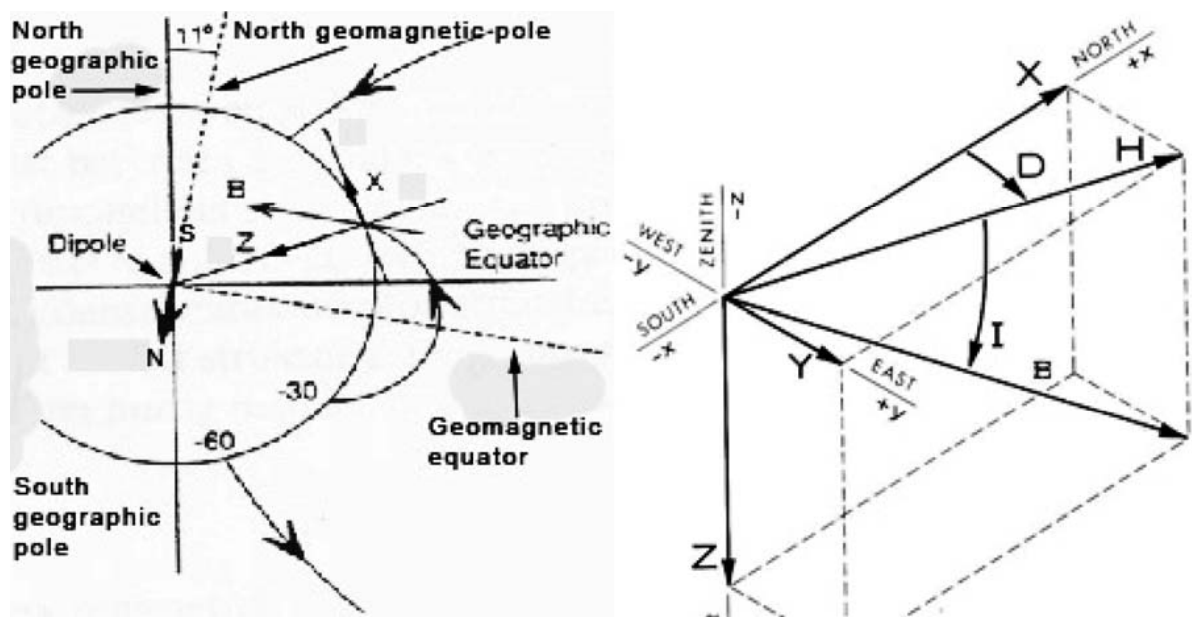

Figure 2. The figure illustrates a simple model of the Earth's magnetic field in a plane. It is assumed that the field is due to a magnetic dipole located in the centre of the Earth. The dotted line, which makes an angle of $\sim 11^{\circ}$ with the geographic axis, is called the dipole axis, and where it intersects with the surface of the Earth, the field is hypothetically vertical. The point where the horizontal component is zero, the vertical component is a maximum and the inclination, or dip is 90 degrees, is called the North Magnetic Dip Pole (NMDP). The latitude is measured from the equator. The magnetic elements, the horizontal component $H$, the vertical component $Z$, the north component, $X$, the east component $Y$, the declination $D$, and the inclination $I$ are marked. The field has the direction as indicated by the arrows. Thus, the Earth's magnetic field is positive pointing downward toward the Northern Hemisphere, and the dipole pole in the Northern Hemisphere is a south pole. Because opposites attract, the south dipole pole attracts the north pole of a compass.

measurement of the magnetic field at any point on the Earth. Because each model or representation of the field has a pole at different locations, there is still confusion over the meaning and location of the magnetic pole. However, the only pole that can be directly measured, is the dip pole, called the NMDP. This is the point on the Earth where the horizontal magnetic component is zero and where the vertical component is maximum; thus it is the spot where a magnetized needle would stand vertically to the Earth's surface; i.e. the inclination is $90^{\circ}$. The search for the NMDP began in earnest around 1800 with the British Royal Navy's campaign to discover the Northwest Passage. Because the NMDP is located where the climate is so extreme and so remotely from where people are living, the task to locate its position was difficult.

James Clark Ross (cf. Commander John Ross's 1835 monograph and lecture at The Royal Society, December 1833, Ross, 1834) reported his magnetic observations during the Victory expedition on the west coast of Boothia Peninsula (Fig. 3). Measurements of NMDP were made by a dip circle instrument, which was a sort of a vertical compass. James Ross measured an inclination of $89^{\circ} 59^{\prime}$ with his dip circle instrument on 1 June 1831. For all practical purposes, he had found the NMDP. The geographic coordinates for the pole were revised by Nippoldt (Nippoldt, 1929) to $70^{\circ} 05^{\prime}$ north (N) and $96^{\circ} 46^{\prime}$ west $(\mathrm{W})$.

It was suggested by Ross, that the magnetic pole had an area of about 50 miles in diameter, for which there was no apparent horizontal force $(1$ statute mile $=1.852 \mathrm{~km})$. Ross's dip circle readings were given for noon, 03:00 p.m.,

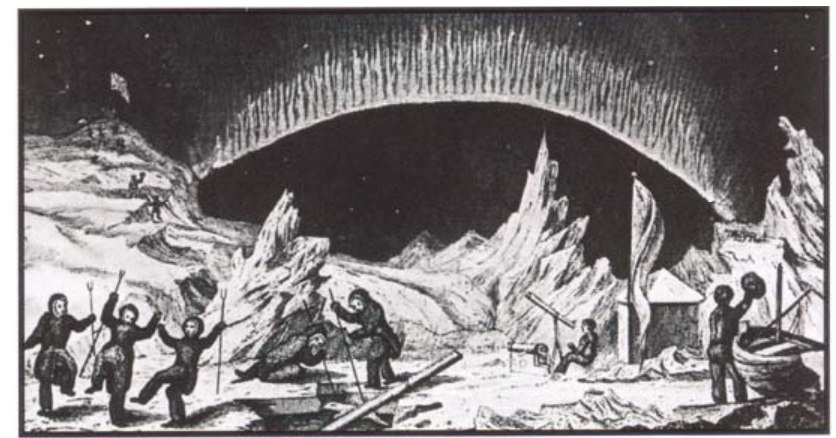

Figure 3. A drawing showing James Clark and co-workers locating the North Magnetic Dip Pole in 1831 (from Ross, 1835).

05:00 p.m. and 07:00 p.m., i.e. four observations. The final value given is the mean of all his readings. The results were variable, which he could not explain. With a simple dip circle instrument, it is difficult to determine accurately the position of the pole. James Ross did not claim to have stood on the very spot of the magnetic pole, but thought he was within $a$ mile or so of the pole. Unfortunately, he did not know that even on a magnetic relatively quiet day, the pole he tried hard to locate can change by about $5 \mathrm{~km}$ in one hour. 
Table 1. For the various magnetic measurements, the Expedition was provided with these instruments. The Reference Name is how the instrument is referred to in the data lists. Units 6, 7 and 8 were recording instruments (see Steen et al., 1933).

\begin{tabular}{llll}
\hline No. & Instrument & S/N & Reference Name \\
\hline 1 & Theodolite Zschau & 289 & Z. \\
2 & Theodolite Seeman & 219 & S. \\
3 & Inclinatorium Dover & 154 & Dover. \\
4 & The Fox-circle & 21 & Fox. \\
5 & Earth-Inductor, Toepfer & & E. I. \\
6 & Eschenhagen variometer & & D \\
7 & Eschenhagen variometer & & $\mathrm{H}$ \\
8 & Eschenhagen variometer & $\mathrm{A}, \mathrm{Z}, \mathrm{C}, \mathrm{D}$ and E, No.7 and 8 & \\
9 & 5 chronometers, plus two pocket models & $\mathrm{I}, \mathrm{II}, 4,5,6$ and 898 \\
10 & Six thermometers & & \\
\hline
\end{tabular}

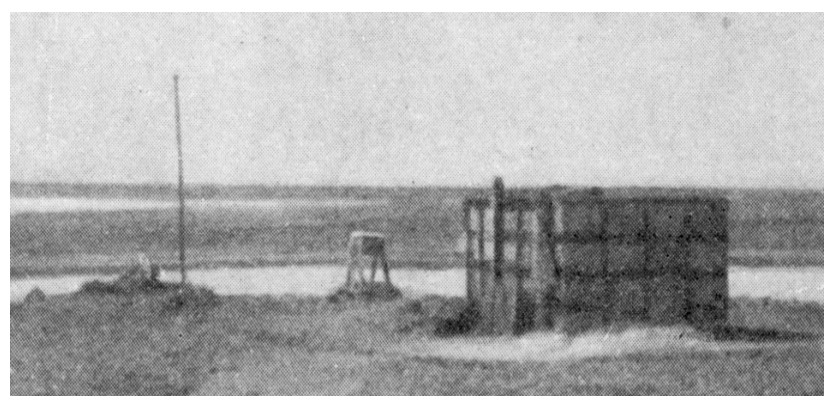

Figure 4. The magnetometer hut at Gjøahavn. The hut was built from shipping cases and non-ferrous metals, it was covered to keep out light and cold. Amundsen suffered CO poisoning to his heart muscle when he remained too long inside, tending the magnetometer (from Steen et al., 1933).

\section{Roald Amundsen's measurements of the magnetic field at Gjøahavn}

On 1 March 1903 the Gjøa Expedition sailed out of Oslo harbor. The preparation and care with which Amundsen approached the polar magnetic studies for the Gjøa Expedition, were unprecedented. Because most previous explorers were constantly moving, there were only point measurements of the field at different places, which gave no indication of the local variations with time. Amundsen followed the advice of experts and established a permanent station approximately $200 \mathrm{~km}$ from the assumed position of the pole and made continuous observations for almost two years. His studies were, no doubt, sparked by the location of the Magnetic Pole near the route of the Northwest Passage. The main purpose was to explore the region and "to determine the present geographical coordinates of the magnetic pole-point".

The magnetic instruments and accessories are listed in Table 1. Altogether three magnetic instruments were chosen with great care in Germany, two were purchased in England, while three were borrowed from the Norwegian Meteorolog- ical Office and from Professor Kr. Birkeland at the University of Oslo. The most important instruments were the standard variographs for the continuous recording of the field. In addition, they had three instruments - inclinatoria, for determine the inclination angle. For recording declination they had two instruments. Some instruments were especially constructed for field observations close to the pole, where the $H$ component is small while $Z$ is large (cf. Steen et al., 1933).

The survey to locate the magnetic pole is in principle similar to a magnetic survey of any other region. However, the climate at the remote location of the magnetic pole imposed several practical constraints. The characteristic properties of the Earth's main field, and its changes, are difficult to measure from one station, and impossible to map accurately by observing over a short period. This is because there are many different contributions to the main geomagnetic field and they are variable.

The permanent magnetic station (Fig. 4) was built by Amundsen and his crew at Petersen bay, on King William Land and was called Gjøahavn. Gjøahavn was well into the polar cap and estimated to be within $200 \mathrm{~km}$ of the NMDP, shown on the map in Fig. 5. The observations were going day and night, without interruption for more than a year and a half. In addition, absolute calibrations were made regularly (Fig. 6). Thus, about 360 absolute measurements of the magnetic elements were carried out. Figure 7 shows the first routine magnetograms from the three variometers for $H, D$, and $Z$.

Eight magnetic field stations, four in the neighbourhood of Gjøahavn, numbered 1, 2, 3 and 4, and four farther away at Boothia Felix, where Ross had reported the location of the pole, called I, II, III and IV, were operated. Their locations (coordinates) are shown in Table 2. Short periodic observations were carried out at the field stations in 1904 and 1905. The average values for the different magnetic elements, as well as the estimated distances to the magnetic pole $(d)$ from the stations are also shown in Table 2 (Wasserfall, 1939). 


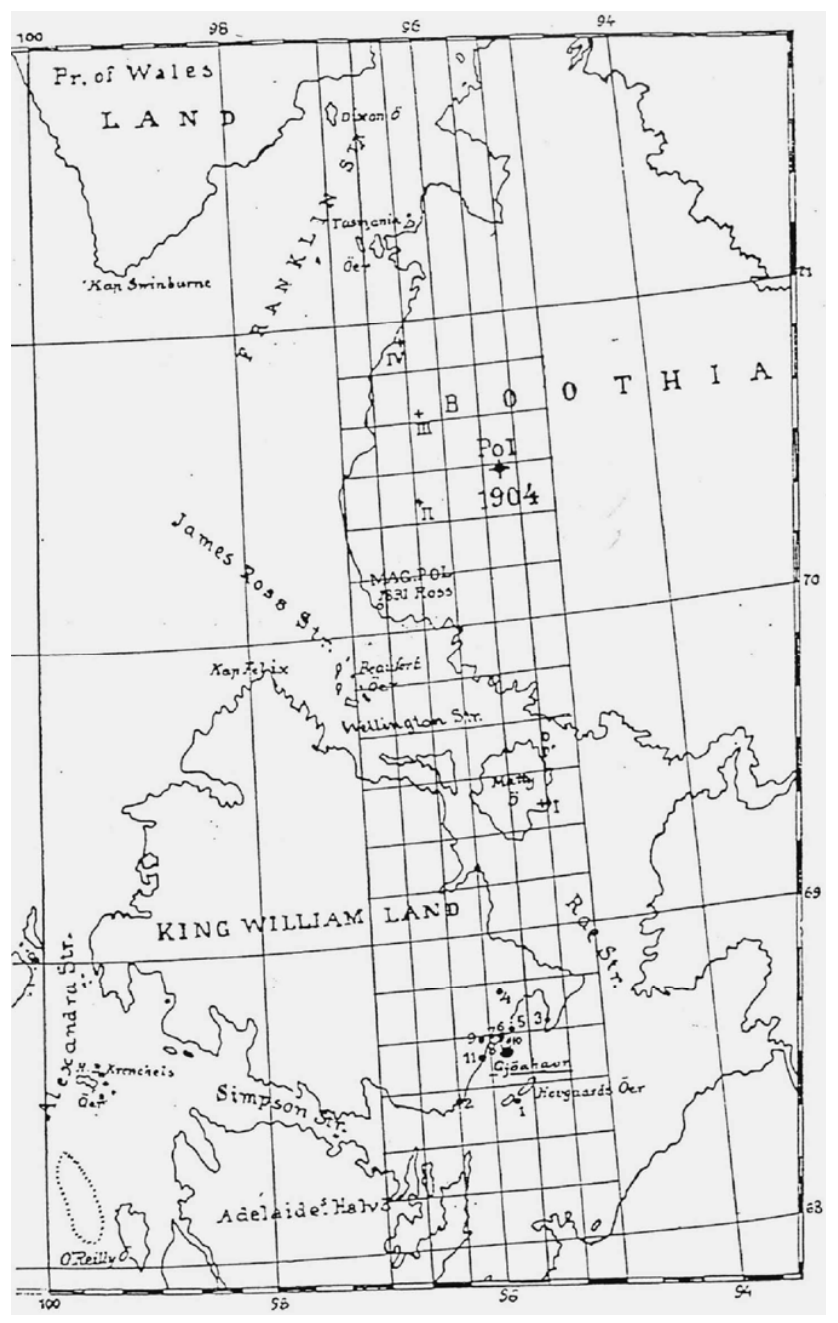

Figure 5. A map of the Canadian archipelago containing the Boothia Peninsula and King William Land. Gjøahavn, the NMDPs, and the temporary magnetic observatories listed in Table 2 are shown.

Amundsen's interest in geomagnetism dominated the scientific efforts during the three years spent on the way through the Northwest Passage. Two over-winterings with magnetic observatories made the data from the expedition unique. On 13 August 1905 they sailed out of Gjøahavn. They stopped in Sitka, Alaska to intercalibrate the magnetic instruments with the magnetometer established there. There Amundsen met Harry Edmonds, who worked for Louis A. Bauer, a driving force in Washington, DC for the improvement of magnetic observations worldwide. Bauer was interested in the magnetic data, and offered to reduce and prepare them for publication. Amundsen, however, felt obligated to have this work carried out in Norway (Silverman and Smith, 1994).

Around 1900, knowledge about geomagnetism was still an emerging science. The expedition was carried through during sunspot cycle 14 . The monthly average number of

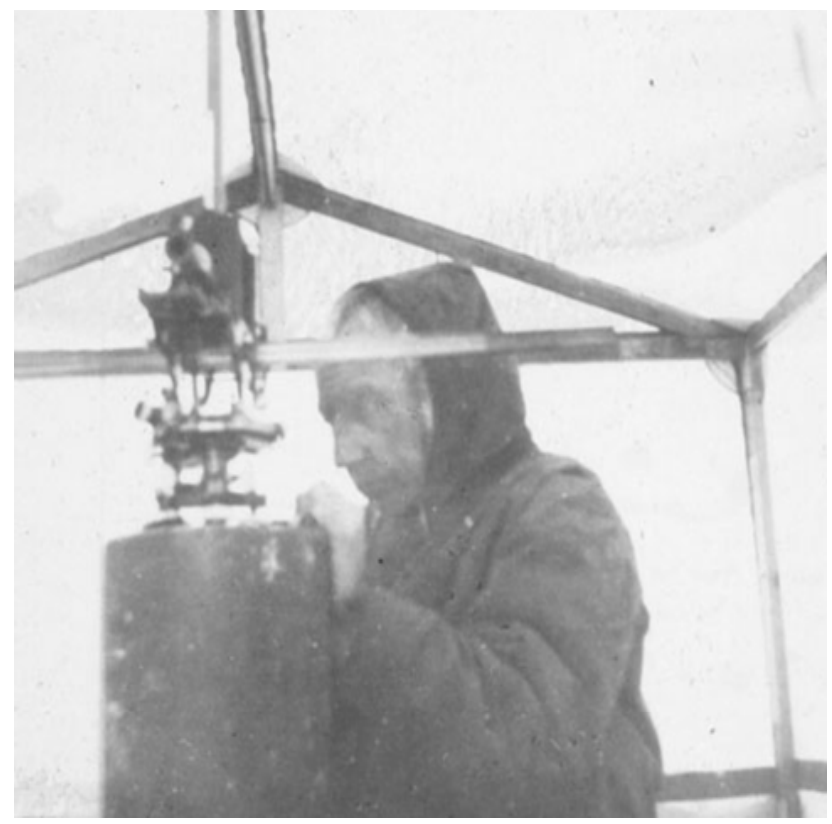

Figure 6. Amundsen making an absolute magnetic measurement during the Maud expedition through the northeast passage (from Amundsen's archives at The FRAM Museum).

sunspots was near 30 in 1903, but increased to 60 in 1905 . Thus, the expedition was carried out during moderately disturbed solar activity. Even if it is difficult today to evaluate the magnetic observations, the recordings indicate high quality.

Amundsen himself has not carried out any detailed analyses of the observations. His few results are published in The Northwest Passage (1908a) and in his lecture at The Royal Geographic Society, on 11 February 1907 (Amundsen, 1908b). He appointed a committee consisting of Aksel S. Steen, Deputy Director at The Norwegian Meteorogical Institute, as chairman, while K. F. Wasserfall, at The Magnetic Byrå in Bergen and meteorologist N. Russeltvedt were the other two members. Particularly Wasserfall had education and experience in geomagnetic studies. The editing of the magnetic observations was not completed before 1932 (Steen et al., 1933). The most complete examination was carried out by Wasserfall in his 1938 and 1939 papers (Wasserfall, 1938, 1939).

An inspection of the magnetic records shows:

1. The average Gjøahavn magnetic values for the 19 months were: $H=760 \pm 100 \mathrm{nT}, D=5.0^{\circ} \pm 3^{\circ}$ and $I=89^{\circ} 17^{\prime} 18^{\prime \prime} \pm 6^{\prime}$. Changes in direction and intensity were large and variable on time scales from minutes to months.

2. A yearly variation with a significant maximum intensity during the summer months is noted (cf. Fig. 8). Other regular periodic variations can not be seen directly, 

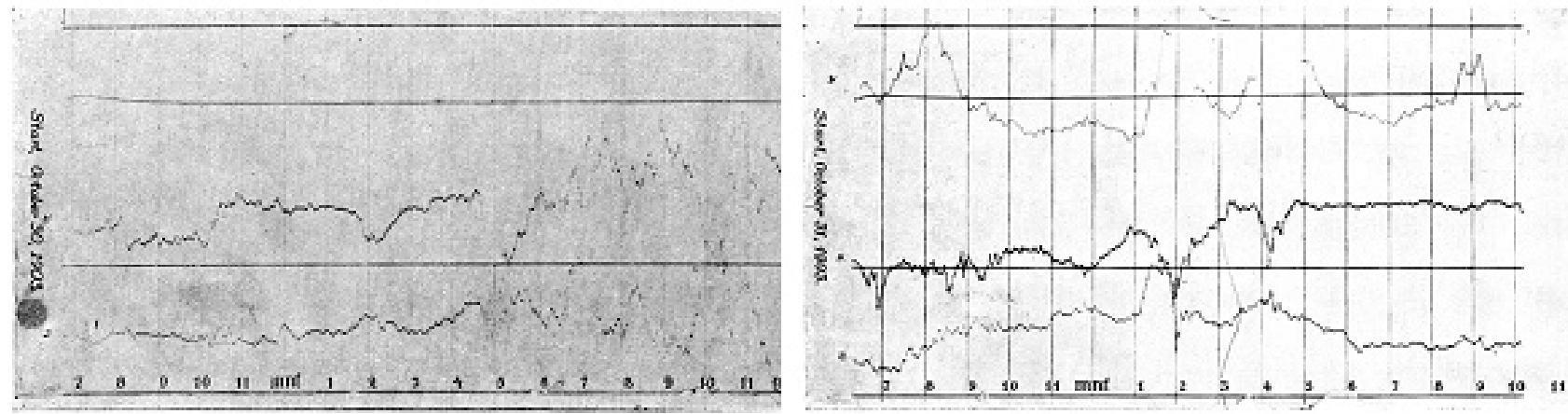

Figure 7. Showing the first routine recordings of magnetic components $H, D$, and $Z$ at Gjøahavn (from Steen et al., 1930). Imagine Amundsen's surprise when the newly-installed Gjøahavn magnetometers recorded one of the largest magnetic storms ever recorded on 31 October 1903 the first day they started the routine measurements (Cliver and Svalgaard, 2007).

Table 2. The nine magnetic observation sites, with geographic coordinates, average values for the magnetic elements, declination $(D)$, horizontal component $(H)$ and inclination $(I)$, are listed. The last column shows the estimated distance to the NMDP. Beechey Island was a station on the route to Gjøahavn.

\begin{tabular}{lccrrrr}
\hline Station & $\phi$ & $\lambda$ & $D$ & $H(\mathrm{nT})$ & $I$ & $d(\mathrm{~km})$ \\
\hline Beechey Island & $74^{\circ} 43^{\prime} \mathrm{N}$ & $91^{\circ} 54^{\prime} \mathrm{W}$ & $128^{\circ} 28^{\prime} \mathrm{W}$ & 1550 & $88^{\circ} 20.0^{\prime}$ & 480 \\
Gjöahavn & $68^{\circ} 37^{\prime} \mathrm{N}$ & $95^{\circ} 53^{\prime} \mathrm{W}$ & $7^{\circ} 24^{\prime} \mathrm{W}$ & 761 & $89^{\circ} 17.4^{\prime}$ & 206 \\
1. & $68^{\circ} 27^{\prime} \mathrm{N}$ & $95^{\circ} 49^{\prime} \mathrm{W}$ & $44^{\circ} 00^{\prime} \mathrm{E}$ & 755 & $89^{\circ} 15.0^{\prime}$ & 229 \\
2. & $68^{\circ} 28^{\prime} \mathrm{N}$ & $96^{\circ} 18^{\prime} \mathrm{W}$ & $2^{\circ} 50^{\prime} \mathrm{E}$ & 900 & & 224 \\
3. & $68^{\circ} 42^{\prime} \mathrm{N}$ & $95^{\circ} 31^{\prime} \mathrm{W}$ & $35^{\circ} 15^{\prime} \mathrm{E}$ & 645 & & 203 \\
4. & $68^{\circ} 48^{\prime} \mathrm{N}$ & $95^{\circ} 56^{\prime} \mathrm{W}$ & $4^{\circ} 10^{\prime} \mathrm{W}$ & 655 & & 190 \\
I. & $69^{\circ} 24^{\prime} \mathrm{N}$ & $95^{\circ} 22^{\prime} \mathrm{W}$ & $35^{\circ} 30^{\prime} \mathrm{W}$ & 410 & $89^{\circ} 36.0^{\prime}$ & 130 \\
II. & $70^{\circ} 25^{\prime} \mathrm{N}$ & $96^{\circ} 18^{\prime} \mathrm{W}$ & $45^{\circ} 40^{\prime} \mathrm{E}$ & 395 & $89^{\circ} 34.0^{\prime}$ & 16 \\
III. & $70^{\circ} 42^{\prime} \mathrm{N}$ & $96^{\circ} 15^{\prime} \mathrm{W}$ & $120^{\circ} 00^{\prime} \mathrm{E}$ & 140 & $89^{\circ} 52.0^{\prime}$ & 23 \\
IV. & $70^{\circ} 56^{\prime} \mathrm{N}$ & $96^{\circ} 21^{\prime} \mathrm{W}$ & $101^{\circ} 30^{\prime} \mathrm{W}$ & 285 & $89^{\circ} 38.0^{\prime}$ & 45 \\
\hline
\end{tabular}

except - during some of the months, a periodic variation of $\sim 28$ days.

3. The largest sunspot maximum appeared between $22 \mathrm{Au}-$ gust and 2 September 1904, "but it did not generate any intense magnetic disturbances". Wasserfall (1939) concluded that the sunspot curve and the magnetic observations for 1904 do not seem to show any general similarity.

The regular diurnal variation in the $H$-component, called the $S q$ variations, is marked during all quiet days. Wasserfall $(1927,1939)$ also mentioned a period of $\sim 3$ days, or $80 \mathrm{~h}$, both in the $H$ and the sunspot data, but they are not shown here.

The periodicity of polar magnetic storms in relation to the solar rotation is of considerable interest. Based on a lot of observations - mainly at low and medium latitudes, a significant period of nearly 27.3 days, the same as the rotation period of the Sun, has been found (Chapman and Bartels, 1940). However, Amundsen's magnetic data from Gjøahavn show a period of 28.3 days (Wasserfall, 1927 and Fig. 9).
For comparison, Professor Birkeland, based on magnetic observations from four high latitude stations during the winter 1902-1903 and from the first International Polar Year 1882-1983, found a period close to 29 days. "Regarding the connection between sun-spots and magnetic storms it seems improbably that the sun-spots can be the direct cause of magnetic storms", Birkeland concluded (Egeland and Leer, 1973). This periodicity is generally diminished during high solar activity.

Regarding a 14-day periodicity, Birkeland's terrella (as a cathode) simulations of the Sun are of interest (Egeland and Burke, 2005). When the charge was sufficiently strong, the rays had a remarkable tendency to concentrate about two spots diametrically opposite to each other, 14 days apart. Both the 28- and the 14-day periodicity are fairly well marked in 1904 data, but the 14-day periodicity is not detected every month (Wasserfall, 1927 and Fig. 10).

The longitudinal distributions of sunspots had a tendency to concentrate along two meridians which have an inter distance of about 180 degrees on the Sun's surface. This 


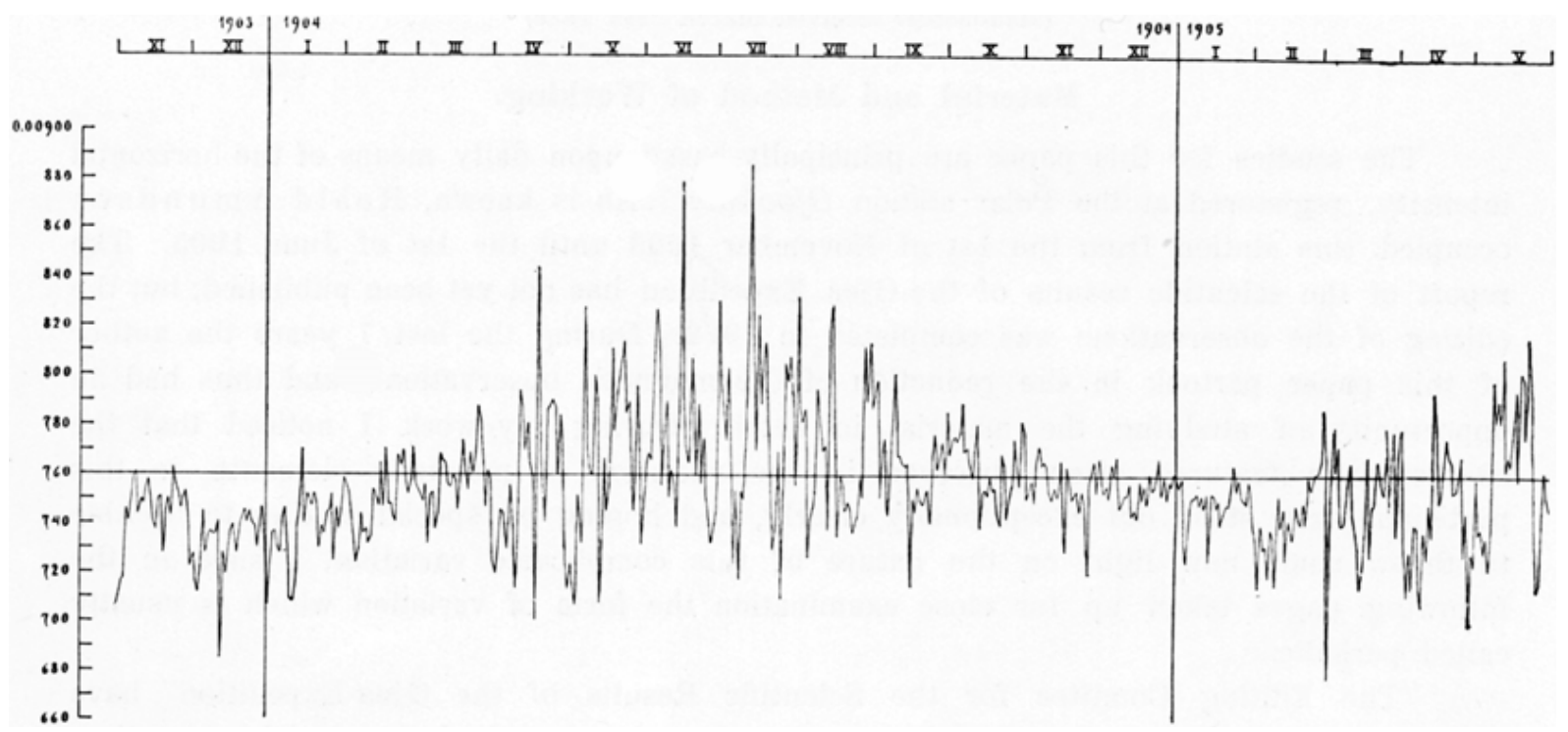

Figure 8. The average daily intensity in nT (vertical scale) of the horizontal component at Gjøahavn from 1 November 1903 to 1 June 1905 , is shown. Notice that the variation from day to day is irregular and large; i.e. about $20 \%$. Furthermore, the seasonal variation shows a marked minimum in the winter months. The oscillations in the daily variations during the summer months are largest. February, March and April 1905 is significantly more disturbed then the same period in the preceding year (from Wasserfall, 1938).

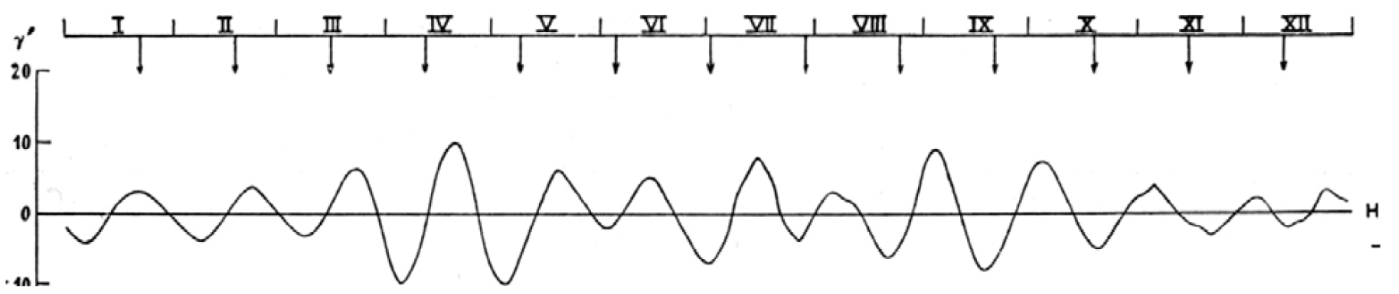

Figure 9. The mean duration of the oscillations in the $H$-component at Gjøahavn for the year 1904 is 28.3 days. The vertical scale is in nT while the months - given by their number, is listed above. This curve shows that the 28.3-day period is maximum during equinoxes. From October to December this period is very weak (from Wasserfall, 1927).

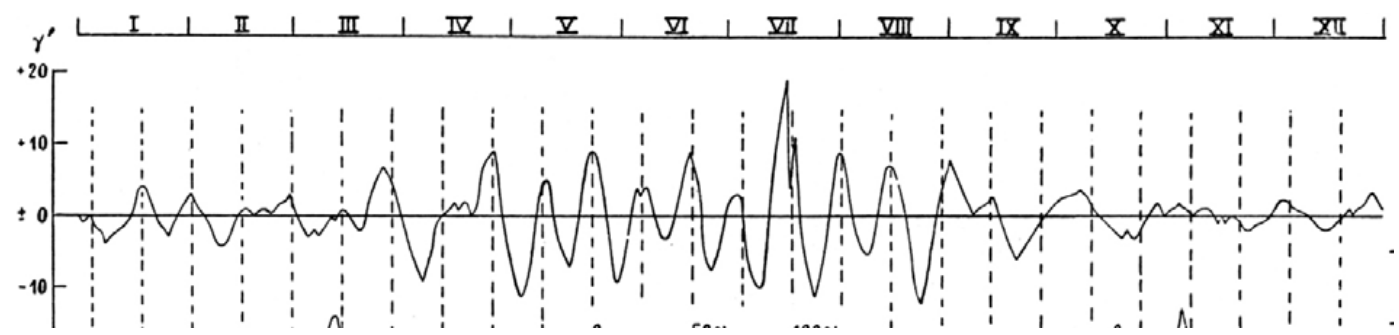

Figure 10. This figure illustrates the 14-day period - actually the period is 14.3 days, for the horizontal component for year 1904 . This period is most marked from March to September (from Wasserfall, 1927). 
peculiarity was one of the most important points from the Gjøahavn results. Thus, the Sun's rotations could cause periodicities of both 14 and 28 days in the Earth's polar atmosphere and in terrestrial magnetism. What Wasserfall could not have known was that the relationship to multiples of the solar rotation period was not connected to sunspots but to high speed streams of solar wind particles from regions of the solar corona called coronal holes. These were not discovered until X-ray pictures of the Sun from spacecraft showed them as dark patches on the Sun, stable for as many as six to ten solar rotations, producing magnetic effects on Earth at regular multiples of the solar rotation (Zhang et al., 2005)

\section{The position of the pole}

The location of the north magnetic dip pole was an important goal of the Amundsen expedition. In the age of sail, when the compass was one of the most important navigational instruments, it was regarded as a legitimate research objective, even though it is of little interest to contemporary scientific studies of the Earth's magnetic field. "Unfortunately, the place on the Earth where the magnetic field is vertical, is neither the magnetic pole nor a geophysically important location" Campbell (2003) concludes in response to recent attempts to locate the NMDP.

For Amundsen it was important to find out if the pole had moved since the Victory expedition. For weeks during 1904, Amundsen and co-workers were hunting for the Pole, but could not pinpoint its position. A few times, they believed they were at its new position, but when they the following day carried out a double check, the dip needle swung far off, indicating that the dip pole now was located farther away. They concluded that the Pole had moved considerably farther northward, between 1831 and 1904. Amundsen discovered that the NMDP "has not an immovable and stationary situation, but, in all probability, is in continual movement" (Amundsen, 1908a). This was a significant result of Amundsen's scientific studies of geomagnetism. He was disappointed because he wrote in his diary: "Our journey was not a brilliant success". He thought he had failed to attain one of his goals.

The geographic coordinates of the Pole as listed by Amundsen in 1904 were $70^{\circ} 30^{\prime} \mathrm{N}$ and $96^{\circ} 30^{\prime} \mathrm{W}$ (Amundsen, 1908b). The coordinates reported by Amundsen, were changed by Wasserfall in 1939 to $70^{\circ} 38^{\prime} \mathrm{N}$, and $96^{\circ} 42^{\prime} \mathrm{W}$. These values probably represent the best obtainable. Accepting these values, the average velocity of the north magnetic pole from 1831 to 1904 has been a couple of $\mathrm{km}$ per year in a northward direction. The next determination of the pole position was carried out by the Canada government scientists shortly after World War II. Changes in the pole position since 1590 is recently discussed by Korte and Mandea (Korte and Mandea, 2008).

In preparation for the expedition, Prof. Schmidt advised Amundsen to locate the permanent observatory at some

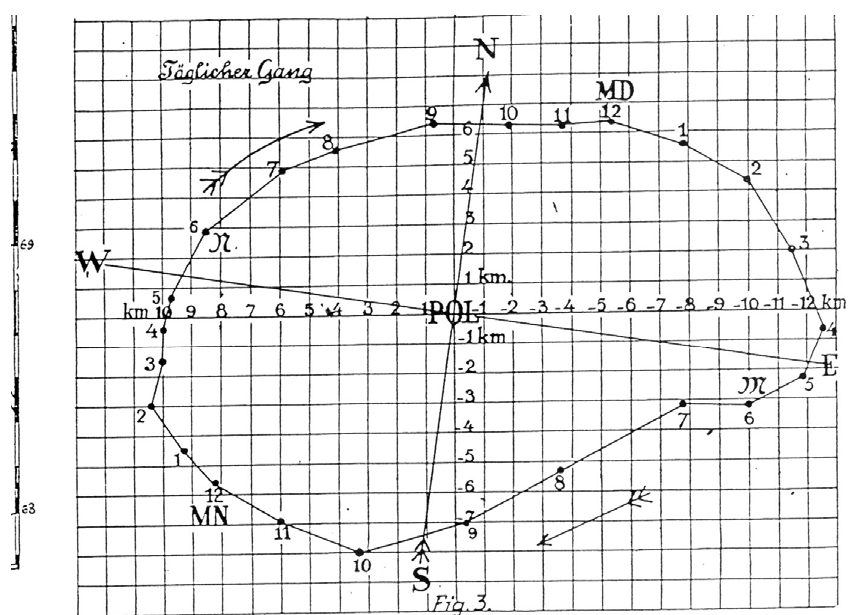

Figure 11. The nearly elliptical curve shows the average diurnal variation of NMDP, observed from Gjøahavn, in 1904. During quiet conditions, the NMDP drifted $10-15 \mathrm{~km}$, while during the summer the drift was typically twice these values (from Graarud and Russeltvedt, 1926)

distance from the suspected location of the pole. He then set out the following values for the magnetic elements in the vicinity of the pole:

Vertical intensity $Z=62000 \mathrm{nT}$

Inclination $I=90^{\circ}-0.5^{\prime} a$, at a distance of $a$ miles

from the pole.

Horizontal intensity $H=9 a \mathrm{nT}$ at a distance of $a$ miles from the pole.

Using these values, and the distance from Gjøahavn to the estimated pole location $(205 \mathrm{~km}$ where 1 mile $=1.852 \mathrm{~km})$, the equations were solved for $a$, so that the one-hour averaged values of the variation of $H$ and $D$ could be substituted giving the variation in $\mathrm{km}$ of the location of the pole. The variation of $H$ yielded the north-south changes in the location of the pole and the variation of $D$ yielded changes in the east-west direction (Graarud and Russeltvedt, 1926).

The result of the calculation of the diurnal variation in pole location is shown in Fig. 11, where the NMDP undergoes a regular, diurnal drift caused mainly by ionospheric current systems, created and driven by sunlight. These variations are larger in summer than during the winter months, but the variations are biggest during very disturbed days. Thus, when we today talk about the location of the pole, we are referring to an average position. The pole wanders daily in a roughly elliptical path around this average position, and may frequently be as much as $25 \mathrm{~km}$ away from this position during disturbed conditions. Figure 12 shows the rather smaller annual variation of the location of the NMDP. 


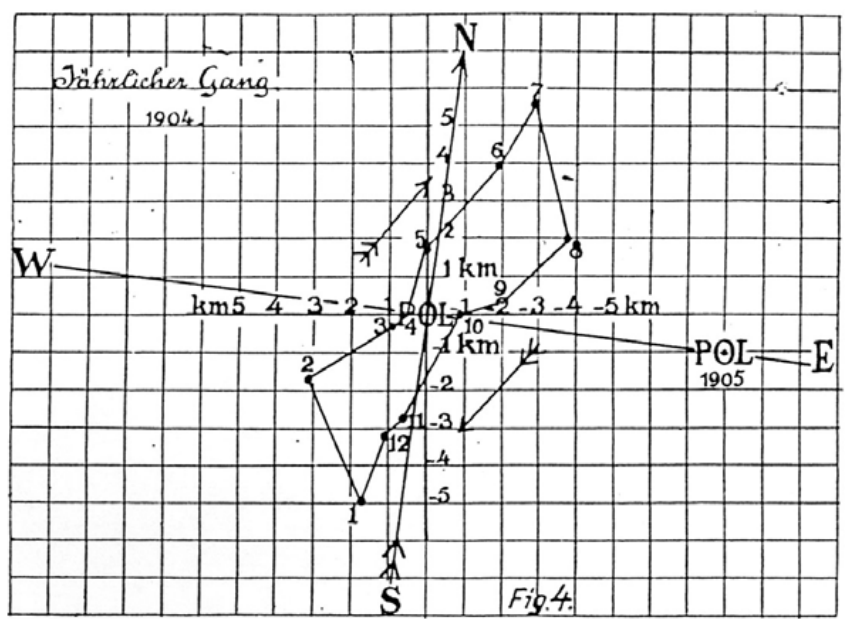

Figure 12. The average annual location of the NMDP observed from Gjøahavn for 1904 (from Graarud and Russeltvedt, 1926).

\section{Solar wind, interplanetary magnetic field and magnetic sector structures}

Interplanetary space, not long ago believed to be empty of matter, is filled with electrons and ions of solar origin. These streaming particles carry with them the solar magnetic field and are collectively called the solar wind. The presence of the solar wind including the interplanetary magnetic field (IMF) was verified as soon as in-situ measurements were carried out (Wilcox and Ness, 1965). Even if its amplitude is only of the order of a few nT, it is an important field which significantly influences disturbances on the Earth. The solar wind together with the IMF is the connecting link between solar activity and geophysical disturbances such as large variations in the Earth's magnetic field and auroras. The 28- and 14-day variations observed are caused by solar particles and are thus of special interest in relation to Amundsen's field measurements. Mainly due to the regular average 27.3 day rotation of the Sun, the IMF is spiral-shaped. Near the Earth, the field makes an angle of about $45^{\circ}$ with the radial direction (Egeland et al., 1973).

Solar observations accumulated over time indicated that the polarity of the field is organized in a regular pattern. The interplanetary sector structures were discovered during the descending phase of sunspot cycle 19, with four stable sectors (Wilcox and Ness, 1965). The field was found to point predominately outward from or inward toward the Sun for about a week at a time and then change in a relatively short time to the opposite polarity. This pattern was found to repeat, with only minor changes, for several rotations of the Sun.

Both the two- and four-sectors - and more complicated patterns, have been shown to be present at different epochs. The two-sector pattern is consistent with the dipole field assumption. The four sector pattern implies a more compli-

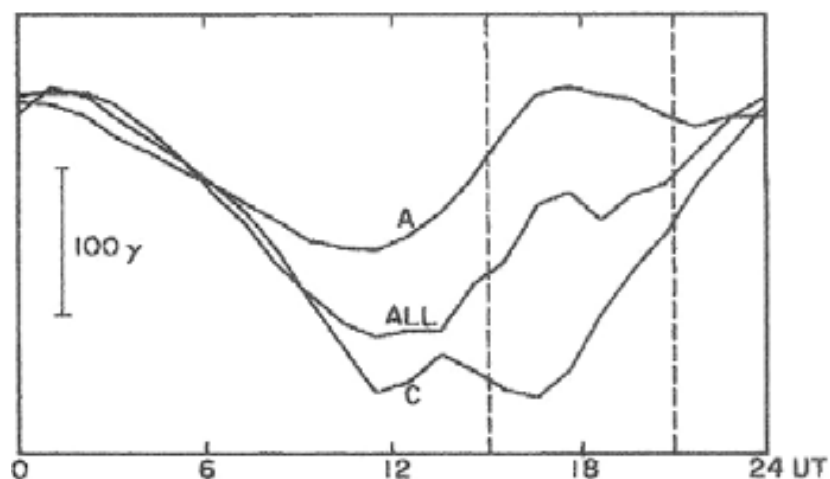

Figure 13a. Diurnal variation of the horizontal component at Godhavn during 1950. The curves labeled $\mathrm{A}$ and $\mathrm{C}$ are the average variations on days classified as being of type $\mathrm{A}$ and of type $\mathrm{C}$, respectively. In the interval, shown by the dashed lines, the largest difference between the two types occurs (from Svalgaard, 1975).

cated solar magnetic field with a wavy neutral sheet (see Sect. 7). The result is shorter intervals of unchanged polarity, but with the same basic period of about 27 days (Egeland et al., 1973; Kivelson and Russell, 1995).

\section{Solar wind, interplanetary magnetic field and magnetic sector structures $100 \mathrm{yr}$ ago estimated from Amundsen's magnetic observations}

The two main objectives of subjecting Amundsen's Gjøahavn data to modern analysis, are: firstly, to show it is equal in quality and accuracy with those of the modern observatories of the late 20th century. Secondly, to learn about the Sun and solar wind activity several decades before polar region magnetic observatories were established. What follows are the Gjøahavn data showing the recently discovered relationship of the high latitude variations of the local magnetic field to changes in the direction of IMF $\boldsymbol{B}_{y}$ and the solar wind.

An objective method of inferring the polarity of the IMF $\boldsymbol{B}_{y}$ component from high latitude magnetic observations was developed by Svalgaard (1972). Named the SvalgaardMansurov Effect (Wilcox, 1972), this discovery led to the development of a new method to infer the IMF direction using the $H$-component observed at Godhavn $\left(69^{\circ} 15^{\prime} \mathrm{N}\right.$, $53^{\circ} 32^{\prime} \mathrm{W}$ ) after 1926 (Svalgaard, 1975). Because Godhavn and Gjøahavn are at roughly the same magnetic latitude, but separated by $\sim 3 \mathrm{~h}$ in longitude, we can subject the Gjøahavn data to the same analysis that was carried out on the Godhavn data. Svalgaard plotted the variation of the one-hour averaged $H$-component from the monthly mean for 1950 from Godhavn. Figure 13b shows the diurnal variations of the onehour averaged Gjøahavn $H$-component of June 1904 from the monthly mean, for (1) all data (middle curve), (2) days when a broad positive perturbation is observed between the 
Gjoahavn Diurnal H Component Variation June 1904

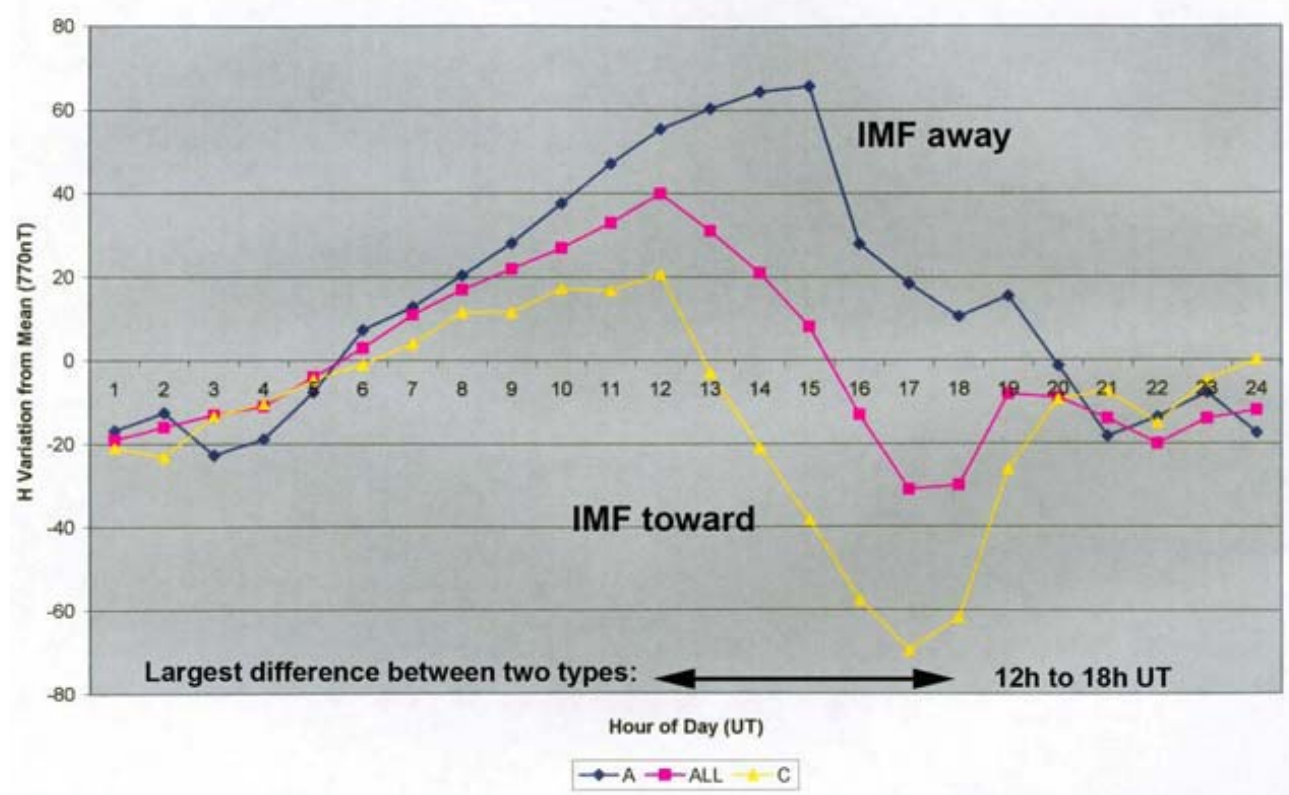

Figure 13b. Diurnal variations of the $H$-component from the monthly mean at Gjøahavn for June 1904 . The blue, red and yellow curves are respectively the average variations of the $H$-component on days with significant away from the Sun sector polarity (a broad positive perturbation), the average value for the whole month and a toward the Sun polarity (i.e. a broad negative perturbation) intensities.

\section{Gjoahavn $\mathrm{H}$ variation by Carrington Rotation}

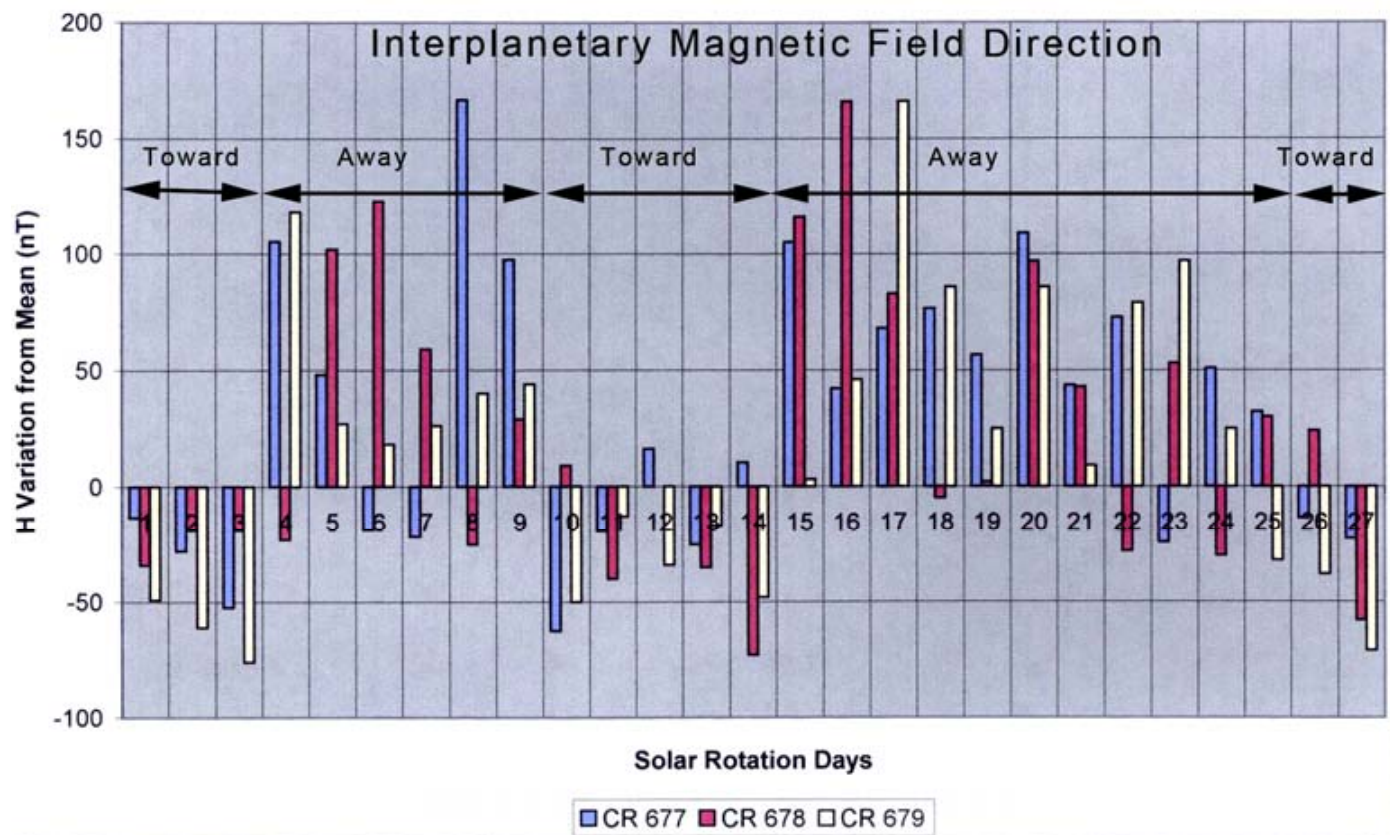

Figure 14. Deviation from the monthly mean of the Gjøahavn magnetic $H$-component for June, July and August 1904 . The data are averaged over the period when the Svalgaard-Mansurov effect is greatest between 12:00 and 18:00 UT each day at Gjøahavn. The days are then assigned to appropriate solar Carrington rotations (CR) and the three CRs are superposed. 


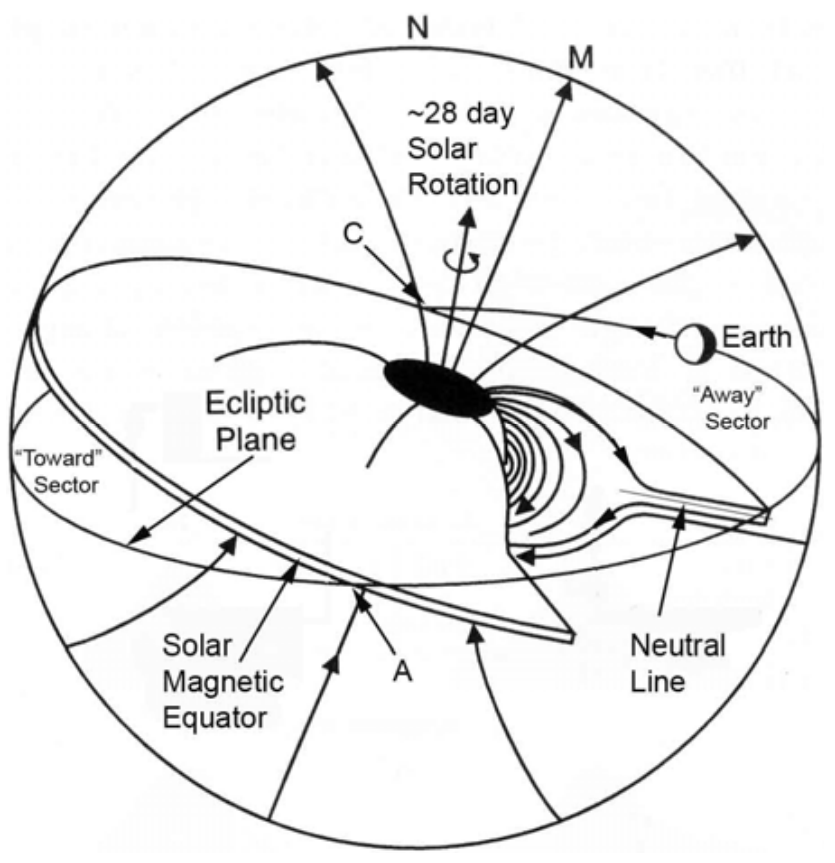

Figure 15a. A schematic three dimensional view of the solar magnetic field carried outward by the solar wind particles and its relationship to the Earth's orbit in the ecliptic plane. Because the solar spin pole is tilted with respect to the ecliptic plane, the solar magnetic field seen at Earth, changes direction twice each solar rotation, changing from "away from the Sun" at point A to "toward the Sun" at point C (modification of figure by Russell, 2001).

hours of 12:00 and 18:00 UT (upper curve: IMF away), and (3) days when a broad negative perturbation in the field intensity is observed between the hours of 12:00 and 18:00 UT (the lower curve: IMF toward). Figure 13a shows similar data, but from Godhavn for 1950 (Svalgaard, 1975).

Taken together, Fig. 13a and b show the nature of both the current systems that affect the diurnal curve of the magnetic variation at stations in the polar cap such as these. Notice that the curves of all of the data (middle curves) are of same sinusoidal character reported by Wasserfall (1938). The difference between the two stations is that the sine waves are out of phase. The reason for this is that the stations pass under sunward-directed ionospheric currents going across the pole that are fixed relative to the Sun, so that the stations pass under the currents, at different Universal Times, resulting in maxima and minima at different times.

It is apparent that we may use this effect on the Gjøahavn $H$-component to infer the direction of the IMF $\boldsymbol{B}_{y}$ component as a function of time to ascertain the nature of the IMF during 1904 (Svalgaard, 1975; Sandholt et al., 2002, p. 54). To do this, we averaged the Gjøahavn $H$ variation for the period 12:00 to 18:00 UT for each day for May, June and July of 1904, and plotted it as a function of time, superposing the three Carrington solar rotations. The result, shown in Fig. 14, indicates that the IMF $\boldsymbol{B}_{y}$ component changed di-

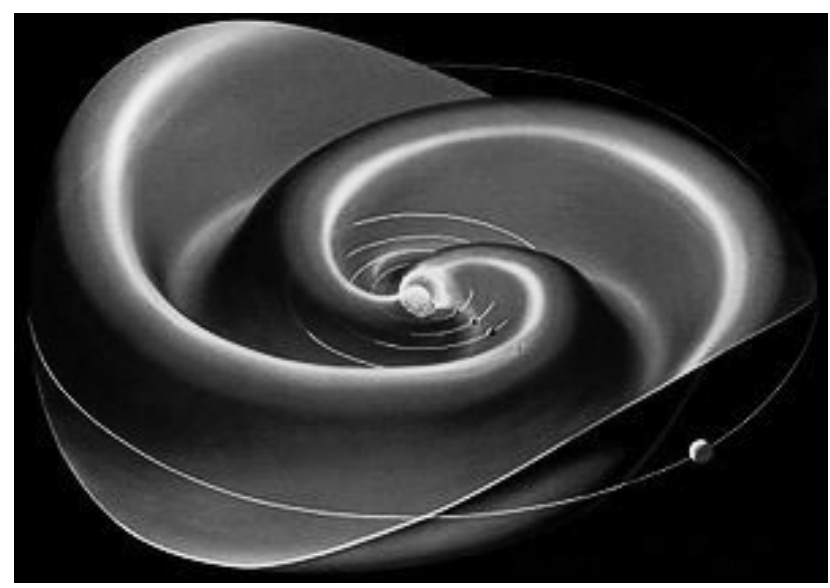

Figure 15b. Similar to Fig. 14a, but showing only the neutral sheet to illustrate the distortion introduced by the departure of the solar magnetic equator from the solar spin equator and resulting in four sector structure crossing per solar rotation as in CR 677-679, observed from Gjøahavn (figure W. Heil, personal communication, 2011).

rection four times each solar rotation during Carrington rotations 677,678 and 679 .

This picture of the interaction of the magnetosphere with the solar wind is consistent with similar conditions today. Note that the period of the Gjøahavn measurements, 19031906 , occurred just as solar activity peaked in solar cycle 14 . Indeed, the magnetospheric storm that occurred on 31 October 1903 was among the largest storms ever recorded (Cliver and Svalgaard, 2004). Figure 15a shows the relationship of the solar magnetic field, carried outward from the Sun by the solar wind, to the Earth's orbital plane. Because the solar spin pole is tilted with respect to the ecliptic plane, the solar magnetic field seen at Earth, changes direction twice each solar rotation when the solar magnetic field equator is undistorted and coincides roughly with the solar spin equator.

For solar activity levels indicated by the sunspot numbers for the years 1903-1906, we would expect to see the solar magnetic equator distorted into a large sine wave on the Sun. The resulting waves in the solar magnetic equatorial plane introduce more interceptions of the Earth by the neutral sheet with each solar rotation. Figure $15 \mathrm{~b}$ shows the neutral sheet forming a "ballerina skirt" that results when the solar magnetic equator becomes significantly distorted, resulting in four sector changes per solar rotation. Because each wave results in two sector changes seen at Earth the number of sector changes is usually even, although changes in the solar magnetic field can occur during one Carrington rotation (CR), leading to an odd number of IMF $\boldsymbol{B}_{y}$ changes during one rotation. It appears, however, that the four crossings during each of CR 677-679, seen in the Gjøahavn data (Fig. 14) is consistent with the solar wind that we see today, $100 \mathrm{yr}$ later. 


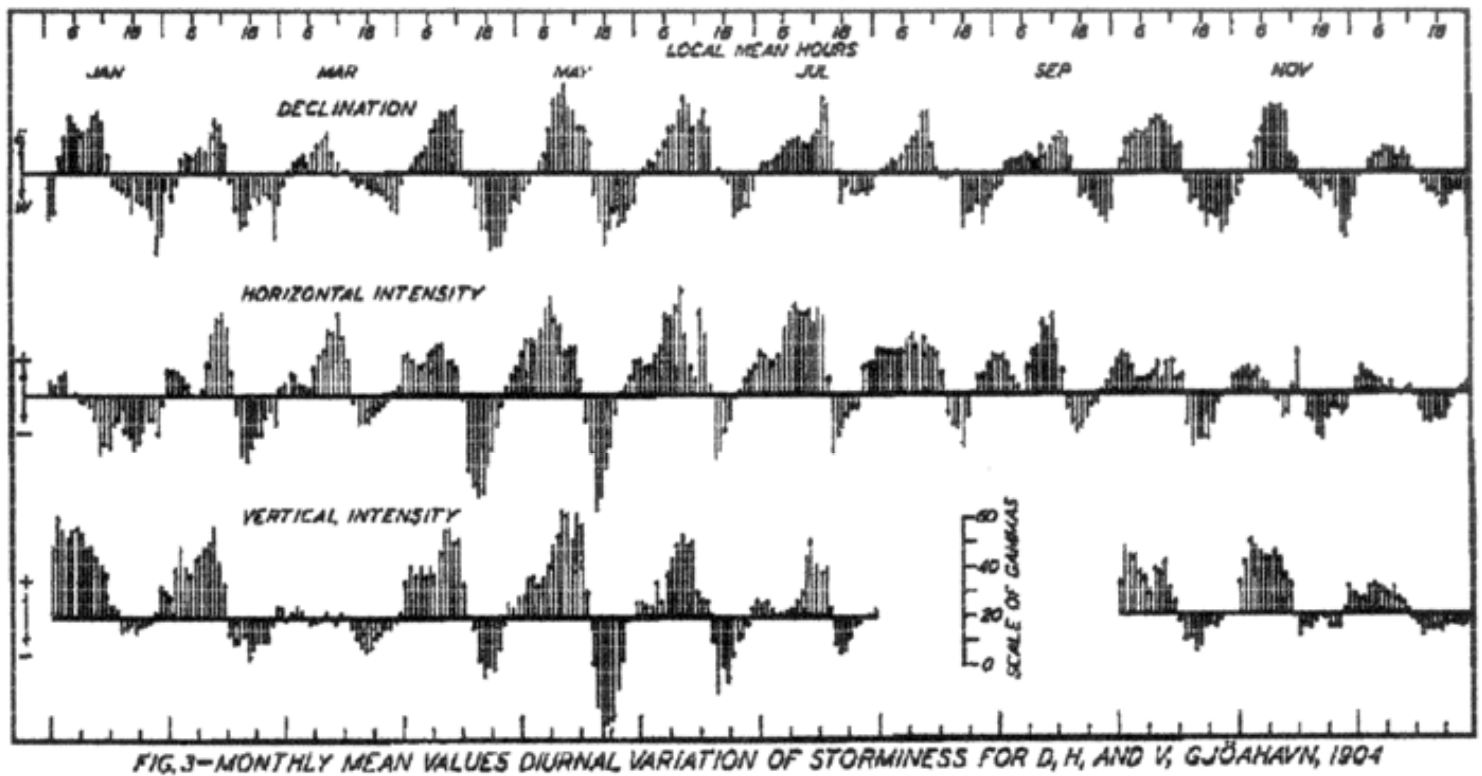

Figure 16. Wasserfall's exposition showing the monthly averaged diurnal variation in all three magnetic components from Gjøahavn for 1903-1904 (from Wasserfall, 1938).

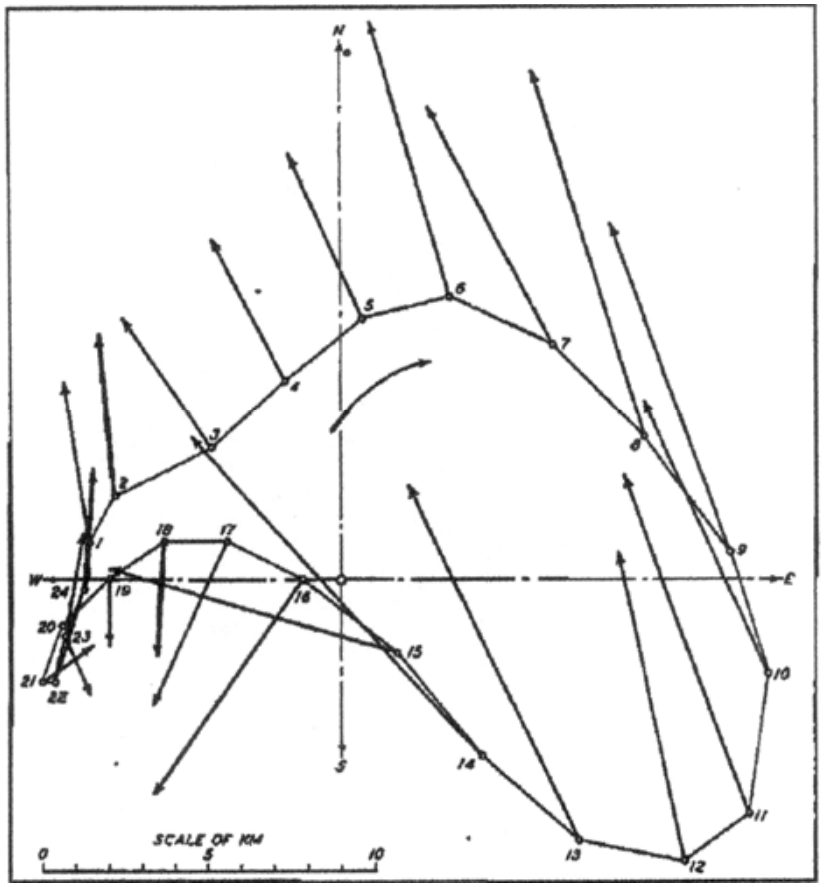

Figure 17a. Wasserfall's analysis of the diurnal variation of the NMDP location averaged for July 1904, as seen from Gjøahavn (figure from Wasserfall, 1938).

\section{Effect of the IMF on the diurnal variation of the NMDP position}

One of the most remarkable aspects of the high latitude magnetograms is the strikingly constant, large diurnal variation of all the magnetic elements. Notice that it generally dominated the traces in the Gjøahavn data, even during periods of auroral activity (Fig. 16). This led to the relatively smooth ellipse found in the calculated diurnal variation of the pole position from data for the entire year (Fig. 11). Wasserfall plotted the July 1904 diurnal variation of the location of the NMDP (Fig. 17a) and found a skewed distribution compared to the regular ellipse shown in Fig. 11. Our plot of the diurnal variation of the location of the NMDP (Fig. 17b) shows the same shape as Fig. 17a for all of the data from June 1904. When we separated the days with IMF Toward and Away from the Sun, we found that the main reason for the skewed distribution of the summer observations, relative to those from the entire year (Fig. 11), was the overwhelming effect of the IMF during that time.

\section{Conclusions}

We have shown that diurnal variations in the Earth's magnetic field observed from Gjøahavn in 1904 are, in part, associated with changes in the IMF $\boldsymbol{B}_{y}$ component through the Svalgaard-Mansurov Effect. The magnitude of the effect, and the character of the variations indicate that the solar 


\section{Diurnal Variation of Dip Pole Location Observed from Gjoahavn June 1904}

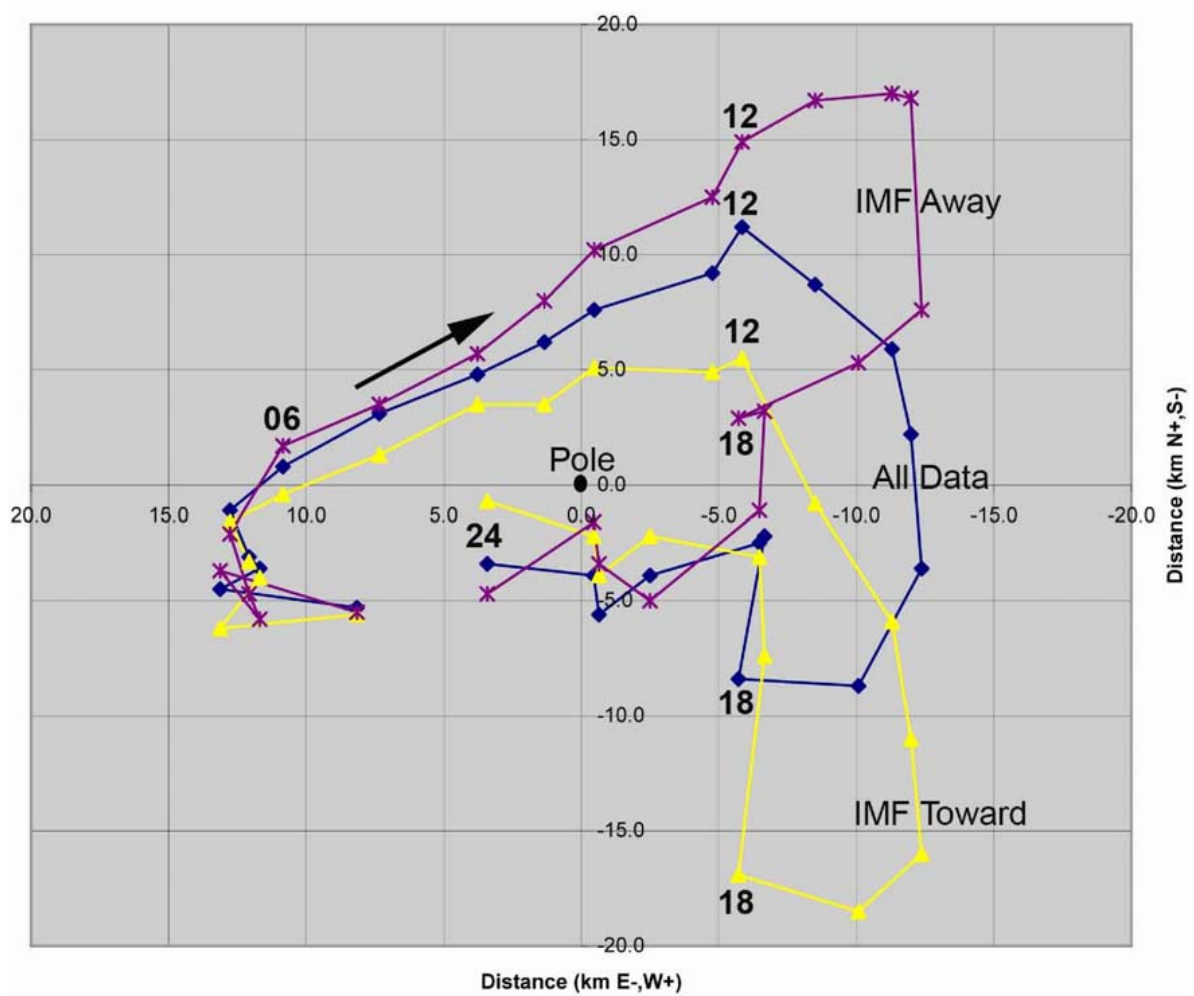

All Data

IMF Toward $\rightarrow$ *IMF Away

Figure 17b. Showing the average diurnal variation of the NMDP location from the June 1904 Gjøahavn data for all days and for days with IMF "toward" and "away" from the Sun.

wind magnitude, direction and occurrence was similar to that which we observe directly today. It is a testament to the scientific abilities of Amundsen himself and his crew to design and carry out the first continuous magnetic variation recording inside the polar cap for a period of 19 months under almost impossible conditions. In addition, the data set is so well-calibrated and corrected, that, besides describing the ordinary geomagnetic disturbances at a high latitude station, we can infer the interplanetary magnetic field structure and direction, for a time $60 \mathrm{yr}$ before its discovery.

Edited by: K. Schlegel

Reviewed by: S. Silverman and M. Korte

\section{References}

Amundsen, R.: The Northwest Passage, Archibald Constable \& Co. Ltd., London, 1908a.

Amundsen, R.: The Northwest Passage, E. P. Dutton \& Co., New York, 1908b.

Brown, L. A.: The Story of Maps, Little, Brown \& Son, New York, 1949.
Campbell, W. H.: FORUM Comment on "Survey Track Current Position of South Magnetic Pole" and "Recent Acceleration of the North Magnetic Pole Linked to Magnetic Jerks", Eos Trans. AGU, 84, 42-43, 2003.

Chapman, S. C. and Bartels, J.: Geomagnetism, Clarendon, Oxford, 1940.

Cliver, E. W. and Svalgaard, L.: The 1859 solar-terrestrial disturbance and the current limits of extreme space weather activity, Sol. Phys., 224, 407-422, 2004.

Egeland, A. and Burke, W.: Kristian Birkeland, The First Space Scientist, Springer, Dordrecht, 2005.

Egeland, A. and Leer, E.: Professor Kr. Birkeland: His Life and Work, IEEE T. Plasma Sci., 14, 666-678, 1973.

Egeland, A., Holter, O., and Omholt, A.: Cosmic Geophysics, Universitetsforlaget, Oslo, 1973.

Gilbert, W.: De Magnete, Peter Short, London, 1600 (1st edn., in Latin).

Gilbert, W.: De Magnete, Basic Books, New York, 1958.

Good, G.: Follow the needle: seeking the magnetic poles, Earth Sci. History, 10, 154-167, 1991.

Graarud, A. and Russeltvedt, N.: Die Erdmagnetischen Beobachtungen der Gjöa-Expedition 1903-1906, Geofys. Publ., III, 3-14, 1926. 
Huntford, R.: The Amundsen Photographs, Atlantic Monthly Press, New York, 1987.

Kivelson, M. G. and Russell, C. T.: Introduction to Space Physics, Cambridge University Press, Cambridge, 1995.

Kløver, G.: Cold Recall, The FRAM Museum, Oslo, 2009.

Korte, M. and Mandea, M.: Magnetic Poles and Dipole Variations, Earth Planets Space, 60, 937-938, 2008.

Nippoldt, A.: Erdmagnetismus und Polarlicht, Einführung in die Geophysik, 2, 1-168, 1929.

Ross, J. C.: On the position of the north magnetic pole, Trans. Phil. Soc. Lon., 124, 47-51, 1834.

Russell, C. T.: Solar Wind and Interplanetary Magnetic Field: A Tutorial, in: Space Weather, edited by: Song, P., Singer, H., and Siscoe, G., Geophysical Monograph 125, American Geophysical Union, Washington, DC, 2001.

Sandholt, P. E., Carlson, H., and Egeland, A.: Dayside and Polar Cap Aurora, Kluwer Academic Publ., 2002.

Schrøder, W., Wiederkehr, K. H., and Schlegel, K.: Georg von Neumayer and geomagnetic research, Hist. Geo. Space Sci., 1, 7787, 2010.

Scott, R. F.: The Voyage of the Discovery: Scott's first Antartic Expedition, Harrison and Sons, LTD, London, 1906.

Silverman, S. M. and Smith, M. E.: Amundsen and Edmonds: Entrepreneurial and Institutional Exploration, in: The Earth the Heavens and the Carnegie Institution of Washington, American Geophysical Union, Washington D.C., 69-79, 1994.

Steen, A. S., Russeltvedt, N., and Wasserfall, K. F.: The Scientific Results of the Norwegian Arctic Expedition in the Gjøa 19031906 under the conduct of Roald Amundsen. Part III, Terrestrial Magnetism Photgrams, Geofys. Publ., Vol. VIII, No. 1, 1-17, 1930.
Steen, A. S., Russeltvedt, N., and Wasserfall, K. F.: The Scientific Results of the Norwegian Arctic Expedition in the Gjøa 19031906 under the conduct of Roald Amundsen. Part II. Terrestrial Magnetism, Geofys. Publ., Vol. VII, No. 1, 1-309, 1933.

Svalgaard, L.: Interplanetary magnetic-sector structure 1926-1971, J. Geophys. Res., 77, 4027-4034, 1972.

Svalgaard, L.: On the Use of Godhavn H Component as an Indicator of the Interplanetary Sector Polarity, J. Geophys. Res., 80, $2717-$ 2722, 1975.

Wasserfall, K. F.: On periodic variations in terrestrial magnetism, Geofys. Publ., Vol. V, No. 3, 3-33, 1927.

Wasserfall, K. F.: On the diurnal variation of the magnetic pole, Terr. Magn., 43, 219-225, 1938.

Wasserfall, K. F.: Studies on the magnetic conditions in the region between Gjoahavn and the magnetic pole during the year 1904, Terr. Magn., 44, 263-275, 1939.

Wilcox, J.: Inferring the Interplanetary Magnetic Field by Observing the Polar Geomagnetic Field, Rev. Geophys. Space Ge., 10, 1003-1014, 1972.

Wilcox, J. and Ness, N. F.: Quasi-stationary Corotating Structure in the Interplanetary Medium, J. Geophys. Res., 70, 5793, doi:10.1029/JZ070i023p05793, 1965.

Zhang, Y., Sun, W., Feng, X. S., Deehr, C. S., Fry, C. D., and Dryer, M.: Statistical analysis of corotating interaction regions and their geoeffectiveness during solar cycle 23, J. Geophys. Res., 113, A08106, doi:10.1029/2008JA013095, 2008. 